\title{
Claves para una estilística de la antropología política de Brigitte Boehm
}

\author{
Keys for a Stylistics of Brigitte Boehm's Political \\ Anthropology
}

\section{Esteban Krotz \\ kroqui@prodigy.net.mx \\ DOI: I0.2490I/rehs.v40iI57.437}

Universidad Autónoma de Yucatán-Universidad Autónoma Metropolitana-Iztapalapa

\section{(c) (7) (8)}

Claves para una estilística de la antropología política de Brigitte Boehm por Esteban Krotz se distribuye bajo una Licencia Creative Commons Atribución-NoComercial 4.o Internacional

Fecha de recepción: 28 de mayo de 2018

Fecha de aprobación: 8 de julio de 2018

\section{RESUMEN:}

Se analiza la obra antropológico-política de Brigitte Boehm Schoendube (1938-2005), particularmente su libro ya clásico Formación del Estado en el México prehispánico, en términos del debate iniciado por el antropólogo brasileño Roberto Cardoso de Oliveira sobre la diversidad de estilos en la antropología. Se perfilan los rasgos de una antropología multisubdisciplinaria, evolucionista y crítica (en el sentido de antiideológico), claramente teórica y situada en América Latina.

Palabras clave:

Antropología del Estado político, el Estado en el México prehispánico, estilo antropológico, Brigitte Boehm Schoendube.

\section{ABSTRACT:}

This essay analyzes the anthropological-political work of Brigitte Boehm Schoendube (I9382005), focusing specifically on her now classic book, Formación del Estado en el México prehispánico (Formation of the State in Pre-Hispanic Mexico), in relation to the debate begun by the Brazilian anthropologist, Roberto Cardoso de Oliveira, on the diversity of styles that exist in the 
discipline of anthropology. It thus profiles the characteristics of a multi-subdisciplinary, evolutionist and critical anthropology (in the anti-ideological sense), that is clearly theoretical and situated in Latin America.

Keywords:

Anthropology of the political State, the State in pre-Hispanic Mexico, anthropological style, Brigitte Boehm Schoendube.

A la memoria de Brixie, en su cumpleaños $80^{\underline{1}}$

Elementos de un estilo de antropología crítica mexicana

La obra de Brigitte Boehm Schoendube puede entenderse como representativa de un determinado tipo de antropología crítica mexicana. Para esbozar este tipo, me centro, en lo que sigue, en su ya clásica obra Formación del Estado en el México prehispánico, libro voluminoso basado en su tesis doctoral.. Trato de extraer de dicho libro tres elementos cuya combinación puede entenderse como indicadores de un estilo de antropología, en el sentido aproximado del significado que le otorgó a este término Alfred L. Kroeber para su análisis de las culturas:

Dado que la cultura humana no puede estar exclusivamente referida a los valores, sino que tienen también que adaptarse a las relaciones sociales (interpersonales) y al mundo real (circunstancias de supervivencia), la totalidad de una cultura difícilmente puede ser considerada por completo como una especie de expansión de un estilo. Sin embargo, los estilos que contienen dicha cultura, incidiendo sobre las demás actividades, pueden influir en la misma. Por consiguiente, todas las partes de una cultura tenderán a acomodarse de algún modo las unas con las otras, de modo que el conjunto puede llegar a impregnarse de una cualidad común y a poseer un grado bastante elevado de congruencia (Kroeber ig69, I46-I47).

También Roberto Cardoso de Oliveira ha utilizado la noción de estilo para caracterizar y explorar comparativamente diferentes tipos o modos -nacionales- de hacer antropología. Aunque los dos autores citados se referían a los resultados de actividades colectivas, trato aquí de aplicar esta idea a una obra individual.

Una antropología multisubdisciplinaria y teórica

En primer lugar, se refleja en la obra de Brigitte Boehm, en general, y en el libro mencionado, en particular, la formación antropológica amplia de la época en la que la Escuela Nacional de Antropología e Historia estaba fuertemente ligada al Museo Nacional de Antropología. En consecuencia, Brigitte Boehm llegó a practicar una antropología que combinaba varias subdisciplinas de modo integral, ya que ella dominaba igualmente los campos de la historiaetnohistoria y de la antropología social-etnología; además, estaba bien familiarizada con los debates y resultados de la investigación arqueológica y manejaba con destreza la lengua náhuatl. Estaba consciente de su multisubdisciplinariedad antropológica que prefería ahondar más y más, 
en vez de hacerse de fragmentos de otras tradiciones disciplinarias en las ciencias sociales. Su vasto conocimiento de la civilización mesoamericana del Centro y Centro-Occidente de México pasada y presente no era solamente resultado del estudio académico, sino que estaba también anclado en el gusto personal por muchas de las facetas de esta civilización -ante todo, la artesanía, la comida y la fiesta- que se evidenciaba rápidamente al observarla en sus actividades cotidianas y en su casa, ya que su manejo fluido de varios idiomas extranjeros y la estrecha familiaridad con la cultura alemana nunca la alejaron de la fascinación por el "México profundo".

En segundo lugar, la antropología de Brigitte Boehm fue siempre una antropología basada en materiales primarios -uno de los legados, sin duda, de su maestro Ángel Palerm-, a quien está dedicado el libro: siempre un trabajo exhaustivo con textos en varios idiomas, con artefactos, con materiales de archivos y entrevistas, con recorridos detallados y a menudo repetidos. ${ }^{4}$ Recuerdo todavía como, cuando trabajaba con códices para su tesis doctoral, me explicó que no entendía cómo se podían analizar estos materiales con fotocopias, ya que éstas en aquel entonces únicamente las había en blanco y negro- solamente permitían interpretar las formas, pero no los colores, los cuales a otros especialistas parecían carecer de importancia.

En tercer lugar, hay que señalar que su antropología combina de modo ejemplar el análisis cualitativo detallado y preciso de un caso específico, con ámbitos socioculturales mayores y con la creación en el plano teórico general; ella queda siempre inmune contra el virus del complejo de inferioridad que a veces ataca al gremio antropológico y que le genera ansiedad por el uso de la estadística o la referencia diligente a propuestas teóricas o temáticas en boga en diferentes países, para permitirle sentirse de algún modo parte de la antropología mundial o de la ciencia social respetable.

En cuarto lugar, no puede dejarse de mencionar que muchos de los trabajos de Brigitte Boehm fueron resultado de su participación en colectivos orgánicos, por llamarlos de algún modo desde "el seminario 'Etnohistoria del Valle de México' que dirigiera Ángel Palerm entre i972 y I976" (Boehm I986, I5) hasta el proyecto "Patrones históricos de usos y manejo del agua en la cuenca Lerma-Chapala-Santiago"-, última aventura investigativa dirigida por ella misma (Sánchez 2006, 9). La mención de este aspecto se antoja importante en vista de la coyuntura que actualmente atraviesan las instituciones académicas mexicanas, donde muchas buenas ideas académicas son convertidas rápidamente en pesadas hipotecas institucionales a causa de su inmisericorde aplicación burocrática. Porque colectivos como los mencionados se basaban en intereses reales de conocimiento comunes y nacieron simultáneamente desde las propuestas de los líderes científicos respectivos y del consenso de diversos investigadores y tesistas ${ }^{5}$ acerca de la utilidad de su participación en el proyecto colectivo de referencia. Podría ser útil reflexionar desde allí sobre las estructuras de la comunidad antropológica en vista del individualismo competitivo promovido por determinadas instancias burocrático-políticas extra e intrauniversitarias que luego pretenden contrarrestar sus efectos más nocivos mediante agrupamientos forzosos que las más de las veces resultan inocuos, simulaciones o contraproducentes para la generación del conocimiento científico en ciencias sociales y humanas. 
Igualmente es de destacar que, a contracorriente de la mezcla perniciosa de criterios empresariales, normas burocráticas y procedimientos provenientes de las ciencias naturalesexactas, que a menudo se critica en el gremio antropológico, pero finalmente se acepta sin resistencia, los estudios de Brigitte Boehm han sido resultados del trabajo pausado y reflexivo, de largo aliento, muchas veces revisados y discutidos con colaboradores y estudiantes, que no buscaban la publicación rápida, sino aportar efectivamente y sobre bases probadas al esclarecimiento de determinadas problemáticas teóricas y sociales.

\section{Una antropología evolucionista desde América Latina}

Como es sabido, los primeros grandes textos de la antropología latinoamericana, que circularon en muchos países del continente y que merecieron pronto también la atención de parte de la antropología mundial, fueron varios estudios del antropólogo brasileño Darcy Ribeiro quien trataba de responder en casi todos ellos a lo que todavía en los setenta del siglo pasado identificó como "la falta de una teoría general explicativa del proceso de formación y transfiguración de los pueblos" (Ribeiro 1992, 62). En México fue, ante todo, el trabajo pionero de Ángel Palerm quien frente a los entonces usuales enfoques sincrónicos y las historias aisladas o de poco alcance reivindicó la importancia de una teoría evolucionista nutrida por múltiples corrientes de pensamiento marxista para la comprensión tanto de la historia de Mesoamérica como de la civilización humana entera y de sus problemas contemporáneos. La compleja interrelación cultura-naturaleza, mediada por el trabajo social y atravesada por las estructuras de poder, que se encuentra en el centro del llamado Modo Asiático de Producción le proporcionaron tanto a él como a Brigitte Boehm un camino fértil ${ }^{6}$ para el análisis del poder, llegando con respecto al pasado a una conclusión que también tiene interés para el mundo actual, en el sentido de que

el origen de la agricultura y de la sociedad compleja no estuvo causado por cambios significativos en el ambiente natural que rodeaba al hombre. Tampoco por inventivas de individuos geniales ni por incursiones casuales de conocimientos generados en el viejo mundo. Las causas se encuentran en la aplicación constante de trabajo a este medio ambiente que, por un lado, produjo un conocimiento acumulado sobre el quehacer natural, por el otro, fue transformando las condiciones de vida de algunas de las especies y variedades que servían de alimento. A la vez, el medio modificado de estas especies produjo en ellas cambios genéticos. En el hombre los efectos provocados en la naturaleza por su trabajo modificaron sus formas de organización y diferenciaron los campos en que seguiría aplicando trabajo (Boehm ig86, 60).

Es importante recordar aquí que los estudios de Brigitte Boehm no solamente se referían al pasado. ${ }^{7}$ Pero incluso cuando éste era el tema, lo aprovechaba para evidenciar lo irracional de los modelos desarrollistas del -como dijera su amigo Guillermo Bonfil- "México imaginario" impuesto por el sistema capitalista cada vez más intensamente "globalizado"; en este libro lo hizo de manera muy plástica: 
La desecación de la cuenca de México y la extracción de los recursos ácueos de las cabeceras de los principales ríos de México hacia el monstruo de ciudad actual están logrando a pasos acelerados convertir todo este territorio en propicio para las especies y variedades que se comen al hombre y a sus basuras: ratas, moscas, cucarachas, virus, bacterias, microbios y demás bichos que, el hombre, a su vez, encuentra difíciles de saborear y digerir (Boehm I986, 47, nota I2).

Finalmente parece pertinente señalar que es justamente en esta relación entre sociedad y medio ambiente donde se presta atención a "distribución y densidad demográfica, patrones de asentamiento, contenidos dietéticos, sistemas de cultivo, de explotación mineral, etcétera", todo lo cual luego es relacionado con elementos lingüísticos e historiográficos (Boehm I986, 356), impidiendo una especie de fetichismo del Estado (capitalista) el cual entonces permeaba ${ }^{-8}$ y sigue permeando buena parte de la antropología política mexicana; el enfoque escogido por Brigitte Boehm permite estudiar las relaciones de poder a partir de su construcción y reconstrucción, tal y como lo hiciera también su amigo y colega Roberto Varela, ${ }^{2}$ fallecido apenas diez meses antes y tan inesperadamente como ella. Este procedimiento permite incluso aventurar que se podría utilizar el apartado final de la obra, escrito para la Cuenca de México de hace mucho tiempo, para pensar la coyuntura actual del proceso de globalización, donde convergencia evolutiva y voluntad de dominación a escala planetaria se combinan:

Cada región contaba con los mismos recursos y con el mismo potencial de dominio que sus vecinas. En términos de su adaptación ecológica puede decirse que habían surgido muchas Teotihuacan. Al encontrarse en situación de competencia, y no de complementariedad, su lucha por la hegemonía culminó en la creación de Tenochtitlan, la cual participaba de los recursos económicos y políticos de cada una, sin identificarse con ninguna (Boehm 1986,359).

Una antropología crítica por antiideológica

La antropología practicada por Brigitte Boehm se nutría de una idea de ciencia que se entendía como opuesta a la ideología: conocimiento sistemático y verdadero, basado en la identificación de relaciones causa-efecto y poniendo en evidencia el discurso interesado por el mantenimiento del statu quo. Es en esta perspectiva que no simplemente festejaba de modo abstracto y sin consecuencias sociales, como en numerosos actos políticos y académicos suele hacerse, "la sabiduría" de "los antepasados", de los campesinos y de los pueblos indígenas. En cambio, partió siempre de la reivindicación práctica y concreta del carácter histórico de las fuentes de "los vencidos". Podría decirse que testimonió, casi a modo, la reivindicación llevada al cabo en circunstancias semejantes un siglo antes por los pioneros alemanes Heinrich Schliemann y Johann Jakob Bachofen con respecto a varias culturas de la Antigüedad mediterránea, el conocimiento acertado de la naturaleza y la sociedad que tuvieron los antiguos habitantes de la Cuenca de México (Boehm 1986, 336); en esta perspectiva estudió también fenómenos socioculturales como las migraciones intrarregionales menospreciadas por "las alusiones al primitivismo" de sus protagonistas (Boehm 1986, 262). 
Sin embargo, esto no implicaba tomar como información verídica la palabra de los estudiados. Al contrario, una y otra vez llegó a criticar la historiografía mexica como ideológica (Boehm I986, 323, 33I I I984, II-I2) y, por consiguiente, a analizarla desde una teoría del mito político, o sea, desde una teoría de la legitimación del poder político (Boehm ig86, I22).

Con esto, Brigitte Boehm se adentraba sin ambages en una perspectiva de clases sociales (Boehm I986, I20 y ss.) hoy poco usual a causa de un repentino proceso sustitutivo de lenguaje teórico

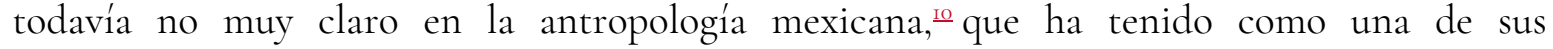
consecuencias también el dejar de lado muchos aspectos "oscuros" de la cultura. ${ }^{\Perp} Y$, sin embargo, tanto en sus estudios sobre el estado prehispánico como sobre el estado postrevolucionario actual, la desigualdad social y cultural es un elemento central. ${ }^{ \pm 2} \mathrm{Su}$ análisis de clase obtiene su agudización por la ya mencionada crítica del modelo de desarrollo vigente y de su evaluación por parte de sus beneficiarios -académicos o no-:

La evolución se mide, entonces, no por los logros unilaterales de una de las partes, sino por una serie de factores referidos a su totalidad: su capacidad de transformar sus recursos energéticos en satisfactores, versus sus desgastes inútiles; su capacidad de garantizar la subsistencia de todos sus miembros; su capacidad de concentrar el poder para fines organizativos sin desposeer a sus partes de los controles propios de su trabajo-medios de producción. En este sentido, la evolución no es siempre progresiva ni significa, tampoco, una clasificación de los grupos en una escala de valores establecida arbitrariamente por los que pretenden encontrarse en sus niveles superiores ( $\underline{\text { Boehm I986, 20)}}$.

Cabe agregar aquí que en sus últimos años, seguramente también a partir de su involucramiento intenso en la dirección de instituciones académicas y en toda una gama de comisiones de evaluación y dictaminación, formuló cada vez con más agudeza críticas acerca de la organización social de la ciencia en México, lo que implicó el escrutinio mordaz de quienes dirigen, administran, controlan y miden la creación de conocimientos científicos en el país. Estaba especialmente preocupada por el papel menospreciado de las ciencias sociales y de la antropología y defendía en muchos foros el carácter peculiar de esta última y el potencial de sus aportes para el análisis de los problemas de la nación y para la construcción de propuestas políticas. ${ }^{13}$

A modo de comentario final

La antropología es, como todas las ciencias, una empresa gremial en la que se conjuntan esfuerzos individuales y colectivos. La estilística que postulaba Cardoso de Oliveira, puede ser un camino para reconocer en estos esfuerzos determinados modos o tipos de hacer antropología, determinadas tendencias de construir conocimiento antropológico -más allá del uso de ciertas referencias bibliográficas-, siempre en peligro de obedecer más a modas pasajeras que al intento obstinado de entender la realidad sociocultural bajo examen. La lectura de la obra de Brigitte Boehm parece mostrar uno de estos estilos que tal vez se encuentre también en otras obras antropológicas mexicanas que podrían ser contadas entre las antropologías latinoamericanas o 
del Sur genuinas. ${ }^{14}$ En todo caso, lo aquí señalado proporciona algunas claves para la lectura y revisión comparativa de una obra de antropología política que se insertó en una antropología irrefutablemente mexicana y al mismo tiempo universal, nacional y mundial, local y global, que quería ver mejor para entender mejor y para poder aconsejar mejor las decisiones pendientes en función de la construcción de lo que actualmente sólo existe como postulado, más lamentablemente no como realidad cotidiana, o sea, la sociedad verdaderamente humana.

\section{Referencias}

CARBONELLA, August y Sharryn KASMIR. 2006. "Rethinking the Anthropology of Social Class". Anthropology News (noviembre): 8-9.

BOEHM, Brigitte. 1984. La formación del Estado en el México prehispánico. Serie Disertaciones Doctorales, I. México: Centro de Investigaciones y Estudios Superiores en Antropología Social.

. 1986. Formación del Estado en el México prehispánico. Zamora: El Colegio de Michoacán.

. 1991. "El Estado en Mesoamérica: estudio sobre su origen y evolución". Revista Española de Antropología Americana (2I): II-5I.

. 1997. Formación del Estado en el México prehispánico. Segunda edición. Zamora: El Colegio de Michoacán.

. 2005. "Buscando hacer ciencia social: la antropología y la ecología cultural". Relaciones Estudios de Historia y Sociedad (XXVI)(IO2): 6I-I28.

2006. Historia ecológica de la Cuenca de Chapala. Zamora y Guadalajara: El Colegio de Michoacán, Universidad de Guadalajara.

CARDOSO DE OLIVEIRA, Roberto. 1995. "Apresentação". En Estilos de antropologia, ed. , 7-II. Campinas: Universidade Estadual de Campinas.

FÁBREGAS, Andrés. 2006. "Brigitte Boehm Schöndube in memoriam". Desacatos (2I) (mayoagosto): $172-176$.

KROEBER, Alfred L. I969. El estilo y la evolución de la cultura. Madrid: Guadarrama.

KROTZ, Esteban. 1993. "La producción de la antropología en el sur: características, perspectivas, interrogantes". Alteridades, año 3(6): 5-II.

2004. "Contribución a la crítica utópica del 'nuevo realismo"'. Metapolítica (Col. Fuera de serie: "I989-2004, la caída del Muro I5 años después"): 226-230. 
2008. "Antropologías segundas: enfoques para su definición y estudio". En Presencia de José Lameiras en la antropología mexicana, ed. José E. Zárate H., 41-52. Zamora: El Colegio de Michoacán.

MENÉNDEZ, Eduardo L. 2002. La parte negada de la cultura: relativismo, diferencias y racismo. Bellaterra: Universidad Autónoma de Barcelona.

MORALES ROSALES, Gustavo E. 2007. "Homenaje a Brigitte Boehm Schoendube". Bricolage (I3) 9396. https://revistabricolage.wordpress.com/2007/04/oi/homenaje-brigitte-boehmschoendube/

RIBEIRO, Darcy. 1992. "La cultura latinoamericana". En Temas de antropología latinoamericana. Colección Antologías 2. Segunda reimpresión de la 5 a edición original del artículo publicado en i978, comp. Germán Martínez Argote, 6i-88. Bogotá: El Buho.

SÁNCHEZ RODRÍGUEZ, Martín. 2006. "Presentación". En Historia ecológica de la Cuenca de Chapala. Brigitte Boehm Schoendube. Zamora y Guadalajara: El Colegio de Michoacán, Universidad de Guadalajara.

VARELA, Roberto. 1984. Expansión de sistemas y relaciones de poder: antropología política del Estado de Morelos. México: Universidad Autónoma Metropolitana-Iztapalapa.

VARIOS AUTORES. 2007. Ciencia: Revista de la Academia Mexicana de Ciencias. "Agua”. 58(3).

Notas

I Tuve la fortuna de que mi relación con Brixie se iniciara prácticamente al mismo tiempo que mi introducción a la antropología mexicana, y que se mantuviera de diferentes maneras a lo largo de los años: desde el disfrute muchas veces repetido de la exquisita hospitalidad de ella y de Pepe Lameiras en Tlalpan, con la siempre encantadora presencia de Luisa, Lorenza y Marina y, ocasionalmente incluso, de sus padres Octavia Schoendube y Federico Boehm, pasando por su actividad como primera secretaria académica del entonces recién fundado Centro de Investigaciones Superiores del INAH (CIS-INAH, hoy Centro de Investigaciones y Estudios Superiores en Antropología Social-Ciesas), en uno de cuyos programas tuve la oportunidad de llevar al cabo mi investigación de tesis de maestría, hasta mis numerosas estancias en Zamora, muchas de ellas en su casa, la mayoría de las veces para impartir un curso intensivo sobre enfoques neoevolucionistas en antropología, que llegó a formar parte integral de su asignatura sobre ecología cultural en el programa de Doctorado en Antropología Social. La relevancia que tuvo para ambos la visión y la praxis de la antropología de Ángel Palerm, el interés compartido por la antropología política y nuestros cuestionamientos semejantes del papel del conocimiento científico-social para el futuro de México, fueron tres importantes ejes de muchas conversaciones, inconclusas desde diciembre de 2005. El presente texto es la versión reelaborada de mi participación en el homenaje que organizó El Colegio de Michoacán en enero de 2007 
(para una breve reseña del mismo, véase Morales 2007), y que ha sido ligeramente revisada para su publicación en Relaciones Estudios de Historia y Sociedad, con motivo de su cumpleaños 80.

2 Uso la primera edición de I986; en I997, El Colegio de Michoacán publicó una segunda edición.

3 Véase para ello la introducción de Cardoso de Oliveira (1995) al libro que recoge los primeros resultados de su proyecto colectivo con este enfoque.

4 Dotada de "una férrea disciplina, un agudo sentido crítico, además del gusto por crear conocimiento" la recuerda Andrés Fábregas (2006, I73).

5 No puede tratarse aquí más el tema, pero merece mención especial la forma y constancia con la que Brigitte Boehm incorporó especialmente durante sus largos años en El Colegio de Michoacán numerosos estudiantes y tesistas a sus investigaciones, no como "recopiladores de datos" en función de sus intereses particulares, sino como aprendices del aspecto central de una ciencia empírica como la antropología. Su preparación de las salidas al campo con ellos, su cuidadosa observación in situ y su manera de entablar relaciones con la población bajo estudio, así como el análisis posterior de la información recabada, aunado al examen meticuloso de textos, mapas y documentos fue para muchos de ellos la decisiva familiarización con la dimensión artesanal de la investigación antropológica -otro aspecto, por cierto, también practicado y enseñado por su maestro Ángel Palerm-.

6 Importantes para ambos fueron los trabajos de Lawrence Krader, repetidamente conferencista y profesor invitado en el entonces CIS-INAH.

7 De hecho, uno de sus últimos trabajos publicados en vida fue un extenso estudio sobre la antropología ecológica reciente y actual (Boehm 2005).

$8 \mathrm{La}$ autora toca este tema también en una discusión sobre los enfoques de J. H. Steward y E. R. Wolf (Boehm 200I, 67).

9 Véase su análisis del sistema político mexicano, Expansión de sistemas y relaciones de poder (Varela I,84).

Io Véase para esto Krotz 2004, 229.

II Alusión al título de una conocida obra de Eduardo L. Menéndez (2002).

I2 Llama la atención en este contexto la observación publicada hace unos años en un boletín estadounidense de antropología: "En el momento presente, cuando el costo humano de la difundida liberalización económica y del revanchismo político crece día con día, es especialmente urgente para los antropólogos atender los problemas de la desigualdad social y de la polarización de las clases. Pero el estudio de las clases ha perdido su aceptación en la antropología" (Carbonella y Kasmir 2006, 8). 
I3 Probablemente le hubiera llamado la atención en este contexto el número monográfico de la revista Ciencia, editada por la Academia Mexicana de Ciencias, que aborda el tema del agua desde los ángulos de la física y de la química, de la geografía y la geología, la biología y la

astronomía - mientras que ninguna ciencia social (aparte de un texto más bien descriptivo al final del número, que versa sobre algunos aspectos de la época prehispánica) fue considerada relevante para el análisis de este problema en México-, cuyo estudio fue una constante en el trabajo científico de Brigitte Boehm Schoendube.

\section{Esteban Krotz}

Es maestro en Antropología Social (Universidad Iberoamericana, Ciudad de México) y licenciado y doctor en Filosofía (Hochschule für Philosophie, Múnich). Labora como ProfesorInvestigador Titular en la Unidad de Ciencias Sociales del Centro de Investigaciones Regionales de la Universidad Autónoma de Yucatán y es docente en la Facultad de Ciencias Antropológicas de la misma universidad y en el Departamento de Antropología de la Universidad Autónoma Metropolitana-Iztapalapa. Sus líneas de investigación son la filosofía y la historia de las ciencias antropológicas (especialmente las Antropologías del Sur), la antropología política y jurídica (especialmente, la antropología de los derechos humanos), la filosofía intercultural y el pensamiento utópico. Recientemente ha editado el volumen colectivo Sociedades mayas y derecho (2015) y elaborado las entradas "Anthropology in Mexico" y "Anthropology and Utopias and Dystopias" para The International Encyclopedia of Anthropology (2018). 